\title{
Kegiatan Survey Kepuasan Pelanggan Jalan Tol Ruas ABC yang dikelola oleh PT. XYZ
}

\author{
Wenda Wahyu Christiyanto \\ wenda.christiyanto@gmail.com \\ Benih Hartanti \\ benih.stiedw@gmail.com
}

STIE PGRI Dewantara Jombang

\begin{abstract}
Abstrak
PT. XYZ dituntut menjadi perusahaan profesional dan modern dalam pengelolaan Jalan Tol, serta memiliki kompetensi yang baik di tingkat nasional dan regional. Oleh karenanya, PT. XYZ melakukan evaluasi layanan dengan mengadakan survey kepada para pelanggan ruas tol ABC, untuk mengetahui tingkat kepuasan serta mengetahui masukan dari para pelanggan. Sumber data dari kegiatan survey ini adalah data primer, di mana diperoleh dengan teknik pengambilan sampel non probabilitas, dengan hasil response rate sebesar $82,25 \%$. Teknik Analisa dalam survey ini menggunakan analisis angka indeks dan analisis deskriptif. Hasil survey dari responden menyatakan bahwa perlu dilakukan peningkatan sosialisasi penggunaan E-Payment, isi ulang E-Toll Card, pemanfaatan GTO, layanan jasa derek gratis, dan layanan Senkom. Selain itu, juga perlu dilakukan pelatihan petugas gardu tol agar lebih ramah, penambahan PJU, penambahan frekuensi patroli petugas PJR, peningkatan respon petugas terhadap kejadian di sepanjang Tol ABC, perbaikan jalan yang bergelombang, pengecekan infrastruktur secara berkala, serta inovasi produk layanan juga hendaknya terus dilakukan, mengingat penilaian pelanggan Tol ABC terhadap layanan Jalan Tol Pembanding semakin baik, meskipun masih tergolong dalam kategori tidak puas.

Kata Kunci : Jalan Tol, Pelayanan Pelanggan, Kepuasan Pelanggan.
\end{abstract}

\section{Abstract}

PT. XYZ is required to be a professional and modern company in the management of Toll Road, and has good competence at national and regional level. Therefore, PT. XYZ conducts service evaluation by conducting a survey to ABC toll road customers, to know the level of satisfaction and to know the input from the customers. Data source from this survey activity is primary data, where obtained by technique of non probability sampling, with result of response rate equal to $82,25 \%$. Analytical Techniques in this survey using the analysis of index numbers and descriptive analysis. The survey results of respondents stated that it is necessary to increase the socialization of E-Payment usage, E-Toll Card refill, GTO utilization, free towing service, and Senkom service. In addition, it is also necessary to train officers toll roads to be more friendly, the addition of PJU, the increasing frequency of patrol officers PJR, increased officer response to events along the ABC Toll, corrugated road improvements, periodic infrastructure checks, and product service innovation also should continue done, given the ABC Toll subscriber valuation of Comparative Toll Road service is better, although it is still classified as not satisfied.

Keywords: Toll Road, Customer Service, Customer Satisfaction.

\section{A. PENDAhULUAN}

\section{Latar Belakang}

Konsep Sentral dari setiap perusahaan jasa adalah memberikan layanan yang baik kepada para pelanggannya, sehingga pelanggan dapat mencapai tingkat kepuasan yang diharapkan, di mana berkontribusi pada sejumlah aspek krusial perusahaan, seperti loyalitas, reputasi perusahaan, efisiensi dan produktivitas (Tjiptono, 2015). .Kepuasan 
merupakan tingkat perasaan di mana seseorang menyatakan hasil perbandingan atas kinerja produk jasa yang diterima dengan yang diharapkan (Kotler, 1997, dalam Lupiyoadi, 2013). Saat ini, baik perusahaan berbasis barang ataupun jasa, harus berorientasi terhadap pelanggan, oleh karena itu diperlukan usaha dalam mengukur kepuasan pelanggan, agar perusahaan dapat mengevaluasi kinerjanya ataupun produknya, sehingga dapat terus berinovasi untuk tetap dapat memenuhi keinginan pelanggannya, di mana keinginan tersebut bersifat dinamis seiring dengan perkembangan teknologi di era modern ini. Dengan tercapainya tingkat kepuasan pelanggan (customer satisfaction) yang tinggi, maka akan tercapai loyalitas pelanggan (Rofiah, C., \& Wahyuni, D. 2017). Faktor utama penentu kepuasan pelanggan adalah persepsi pelanggan terhadap kualitas jasa (Zeithaml dan Bitner, 1996, dalam Lupiyoadi, 2013). Perusahaan yang tanggap dan peduli terhadap pelangganya adalah perusahaan yang mampu mengenali pelanggannya, karena pelanggan akan bereaksi manakala kondisi yang diharapkan tidak mampu dipenuhi oleh perusahaan. Faktor yang dapat menyebabkan keadaan faktual pelanggan menurun di bawah tingkat layak dikarenakan adanya kekurangan terkait dengan produk (Hansen dan Mowen, 2001). Faktor lain yang mempengaruhi kondisi aktual pelanggan adalah persepsi pelanggan terhadap produk layanan tersebut (Rohim, A., \& Arvianto, S. (2017)

PT. XYZ sebagai salah satu perusahaan yang bergerak di bidang pengelolaan Jalan Tol di Indonesia, memilki tanggung jawab untuk memberikan pelayanan publik dalam bidang pelayanan Jalan Tol. Sebagai upaya peningkatan kinerja, PT. XYZ selalu berupaya untuk memaksimalkan pelayanan kepada para pengguna Jalan Tol. PT. XYZ dituntut untuk menjadi perusahaan yang profesional dan modern dalam bidang pengelolaan Jalan Tol, serta berdaya saing tinggi di tingkat nasional dan regional, sesuai dengan yang sudah digariskan dalam visinya. Ruas Jalan Tol ABC adalah salah satu ruas Jalan Tol yang dikelola oleh PT XYZ. Pertumbuhan jumlah kendaraan pribadi dan armada bisnis menyebabkan volume kendaraan yang melintas di Tol ABC semakin meningkat. Hal ini menuntut PT. XYZ, selaku pengelola Tol ABC untuk terus berinovasi untuk mengatasi kepadatan lalu lintas di ruas Tol tersebut, mengingat saat ini masyarakat cenderung memiliki pemikiran yang kritis dalam segala hal.

Dengan meningkatnya pengetahuan masyarakat sebagai pengguna Jalan Tol, pada akhirnya berdampak pada peningkatan daya pemikiran kritis pelanggan terhadap layanan yang tersedia di Jalan Tol ABC, oleh karena itu PT. XYZ harus mengevaluasi kinerja pelayanan yang telah dilakukan berdasarkan persepsi pelanggan. Di samping itu, PT. XYZ juga harus mampu mengidentifikasi perubahan ekspektasi pelanggan atas produk pelayanan yang diberikan. Hasil penilaian kinerja pelayanan yang diberikan oleh pelanggan dan harapan pelanggan terhadap produk pelayanan, selanjutkan akan menjadi masukan bagi perbaikan kualitas kinerja layanan dan pengembangan produk pelayanan PT. XYZ. Dengan demikian, maka diharapkan PT. XYZ bisa terus melakukan inovasi untuk memberikan layanan yang terbaik bagi para pengguna Tol ABC. Dalam rangka menjawab tantangan dinamika tersebut, maka PT. XYZ melakukan agenda temu pelanggan yang bertujuan untuk mendekatkan diri dan menjalin komunikasi kepada para pengguna Tol ABC, sehingga dalam acara Temu Pelanggan tersebut juga digunakan untuk menghimpun saran dan masukan dari pelanggan, serta melakukan survey tentang layanan yang diberikan oleh PT. XYZ. 


\section{Ruang Lingkup Survey}

Ruang lingkup suvey ditujukan pada pelanggan yang mengikuti acara temu pelanggan yang diselenggarakan PT XYZ berdasarkan pada output yang ingin dicapai dalam survey ini, yaitu meliputi:

a. Opini Pelanggan, yaitu mengetahui opini pelanggan terhadap produk dan layanan $(E-$ Toll Card, GTO, Top Up E-Toll Card, Layanan Derek Gratis, dan Layanan Senkom) yang telah disediakan oleh PT XYZ, selaku pengelola jalan tol ABC.

b. Ekspektasi Pelanggan, yaitu mengetahui harapan pelanggan terhadap produk dan layanan (Layanan Transaksi, Lalu Lintas, dan Konstruksi) yang telah disediakan oleh PT XYZ, selaku pengelola jalan tol ABC.

c. Pengukuran Indeks Kepuasan Pelanggan Tol ABC terhadap Jalan Tol Pembanding. Pengukuran Indeks ini dimaksudkan untuk mengetahui tingkat kepuasan pelanggan Tol ABC yang pernah berkendara melalui Jalan Tol DEF.

\section{B. METODE PELAKSANAAN KEGIATAN}

Kegiatan survey dilaksanakan pada saat acara temu pelanggan. Sumber data dari kegiatan survey ini adalah data primer, yaitu jenis data yang diperoleh secara langsung dari responden untuk keperluan analisis melalui pengisian kuesioner oleh peserta. Teknik pengambilan sampel pada kegiatan survey ini dilakukan dengan pendekatan non probabilitas, yaitu sampling insidental, di mana pengambilan sampel berdasarkan kebetulan (Maholtra, 2005), dalam hal ini yang dijadikan sampel adalah Pelanggan Jalan Tol ABC yang mengikuti kegiatan temu pelanggan. Dari 400 Kuesioner yang dibagikan kepada 410 peserta, yang diterima kembali oleh panitia acara sebanyak 329 Kuesioner, sehingga dapat disimpilkan bahwa response rate pada survey ini adalah sebesar 82,25\%.Teknik Analisa dalam survey ini mengguankan analisis angka indeks dan analisis deskriptif, dengan perhitungan sebagai berikut :

a. Perhitungan Indeks Kepuasan Pelanggan (Customer Satisfaction Index). Indeks Kepuasan Pelanggan (Customer Satisfaction Index) dihitung dengan cara merataratakan skoring jawaban responden atas indeks kepuasan pelanggan.

b. Pengolahan Ekspektasi Pelanggan Atas Produk Layanan Yang Diberikan Perusahaan. Pengolahan data hasil penggalian ekspektasi pelanggan atas produk layanan yang diberikan perusahaan dilakukan dengan cara menentukan prioritas dan bentuk usulan tindak lanjut atas ekspektasi pelangan.

c. Pengukuran Pencapaian Beberapa Indikator Terkait Fokus Pelanggan. Pengolahan pencapaian indikator-indikator terkait fokus pelanggan dilakukan dengan cara menghitung prosentasi jawaban responden yang sesuai harapan dibandingkan dengan jumlah total jawaban responden, dengan contoh sebagai berikut :

Tabel 1. Pengukuran Pencapaian Indikator Fokus Pelanggan

\begin{tabular}{|l|l|l|}
\hline \multicolumn{1}{|c|}{ Indikator } & $\begin{array}{c}\text { Kode Jawaban } \\
\text { yang sesuai } \\
\text { Harapan }\end{array}$ & Pencapaian Indikator \\
\hline $\begin{array}{l}\text { Pelanggan } \\
\text { mendengarkan radio } \\
\text { saat berkendara }\end{array}$ & Jawaban "Ya" & $\frac{\sum \text { Jawaban"Ya" }}{\text { TotalJawaban }} \times 100 \%$ \\
\hline $\begin{array}{l}\text { Pelanggan pernah } \\
\text { menggunakan e-toll } \\
\text { card }\end{array}$ & Jawaban "Ya" & $\frac{\sum \text { Jawaban"Ya" }}{\text { TotalJawaban }} \times 100 \%$ \\
\hline
\end{tabular}

COMVICE, Vol 2 No 1, April 2018

http://ejournal.stiedewantara.ac.id/index.php/COMVICE/article/view/123 
Sumber: Data diolah, 2018

\section{HASIL KEGIATAN}

PT. XYZ, selaku pengelola Jalan Tol ABC, mengadakan acara Temu Pelanggan, di mana acara ini diadakan dalam rangka menjalin silaturahmi antara PT. XYZ dengan para pelanggannya. Acara ini dikemas dalam bentuk berbagai hiburan untuk menghibur para pelanggan Jalan Tol ABC. Selain acara hiburan, dalam acara Temu Pelanggan ini, para pelanggan diminta untuk mengisi kuesioner, dalam rangka peningkatan layanan PT. XYZ.

Dalam kegiatan survey yang dilakukan dalam acara Temu Pelanggan tersebut, dibagikan sebanyak 400 kuesioner. Dari 400 kuesioner yang dibagikan, kuesioner yang dikembalikan berjumlah 329, sehingga dapat disimpulkan bahwa tingkat partisipasi dalam survey ini adalah sebesar 82,25\%. Adapun hasil analisis deskriptif dan pembahasan survey dalam acara Temu Pelanggan tersebut tampak bahwa, sebagian besar pengguna tol sudah pernah dan masih menggunakan E-Payment $(77,51 \%)$, dengan alasan praktis $(55.93 \%)$ dan cepat $(21,58 \%)$. Namun, masih ada pelanggan yang masih belum memanfaatkan E-Payment (19,76\%) dengan alasan dominan masih belum tahu cara mendapatkannya dan perlu sosialisasi tentang produk E-Payment tersebut $(10,33 \%)$. Adapun beberapa pelanggan pernah menggunakan, namun saat ini tidak lagi menggunakan E-Payment (2,74\%), dengan alasan kartu E-Payment sering tertinggal di rumah $(2,74 \%)$.

Penggunaan E-Payment tentunya membutuhkan dukungan infrastruktur, yaitu berupa Gerbang Tol Otomatis (GTO) untuk menunjang pembayaran tarif tol tunai. Saat ini di Tol ABC telah tersedia beberapa GTO di setiap gerbang Tol ABC. Berdasarkan hasil survey pada Gambar 2 di atas, dapat menjelaskan bahwa sebagian besar pengguna Tol ABC sudah pernah dan masih menggunakan GTO untuk membayar tarif tol secara non tunai $(77,51 \%)$, dengan alasan dapat mengurangi antrian $(65,96 \%)$, mempercepat transaksi $(16,72 \%)$, dan memudahkan transaksi $(16,11 \%)$. Adapun beberapa pelanggan belum pernah menggunakan GTO $(19,76 \%)$, serta sebagian kecil pernah menggunakan, namun tidak lagi menggunakan GTO, dengan alasan GTO malah bikin macet, karena ketika volume kendaraan tinggi, GTO lengang dan hanya dimanfaatkan pelanggan yang mempunyai E-Toll Card.

Dalam pengelolaan Jalan Tol ABC, PT. XYZ selaku pengelola menyediakan jasa layanan derek untuk membantu pelanggan Tol yang mengalami permasalahan mesin atau mogok. Jasa Derek ini disediakan secara gratis, dan siap mengantar pelanggan sampai ke pintu gerbang terdekat. Berdasarkan hasil survey yang dipaparkan pada Gambar 3, maka dapat diketahui bahwa sebagian besar pengguna tol telah mengetahui adanya jasa derek ini $(72,64 \%)$, para pelanggan berpendapat bahwa jasa derek ini sangat membantu pelanggan yang mengalami mogok di sepanjang jalan Tol ABC (31\%), sebagian kecil pernah menggunakan jasa derek tersebut $(2,13 \%)$, dan sebagian besar pernah melihat keberadaan jasa derek ini (39,51\%). Adapun sebagian kecil pengguna tol masih belum mengetahui keberadaan jasa derek ini (27.36\%), sehingga mereka berharap PT XYZ untuk lebih intensif melakukan sosialisasi tentang Jasa Derek kepada pengguna Jalan Tol $(20,97 \%)$. Namun sosialisasi yang dilakukan tidak sekedar bersifat umum, namun juga termasuk sosialisasi teknis, prosedur dan ketentuan penggunaan Jasa Derek tersebut, agar tidak mengecewakan pelanggan di kemudian hari. 
E-Toll Card sebagai alat pembayaran non tunai tarif tol, bersifat layaknya kartu debit. Apabila limit nominal dalam E-Toll Card sudah habis, maka dapat diisi kembali melalui Gerbang Tol terdekat, Indomaret dan ATM. Berdasarkan hasil survey pada Gambar 4 dapat diketahui bahwa sebagian besar pengguna Tol telah mengetahui lokasi pengisian ulang E-Toll Card (87,23\%). Sebanyak 13,37\% mengetahui informasi isi ulang E-Toll Card dari Banner yang dipasang di Indomaret, dan sebanyak 72,64\% pengguna tol sudah pernah melakukan pengisian ulang baik di ATM, Indomaret ataupun Gerbang Tol terdekat. Namun masih ada sebanyak 12,77\% pelanggan tol yang belum mengetahui lokasi pengisian ulang E-Toll card, sehingga mereka berharap pengelola Jalan Tol perlu terus melakukan sosialisasi kepada masyarakat tentang lokasi pengisian ulang E-Toll Card (10,33\%).

PT. XYZ, selaku pengelola Tol ABC, telah menyediakan layanan Sentra Telekomunikasi (Senkom) yang dapat dimanfaatkan pelanggan untuk menginformasikan tentang situasi lalu lintas, kejadian lalu lintas, ataupun permohonan pertolongan di sepanjang Tol $\mathrm{ABCl}$. Berdasarkan hasil survey dalam Gambar 5, dapat diketahui bahwa sebagian besar pengguna Tol mengetahui tentang layanan Senkom (71,12\%). Mereka berpendapat bahwa informasi nomor layanan Senkom yang dipasang di sepanjang Tol ABC tersebut informatif (28,27\%), sangat membantu (25,84\%), eye catching atau mudah dilihat selama berkendara di tol $(15,81 \%)$, bahkan beberapa pengguna Tol pernah menelefon $(1,22 \%)$, namun ada juga yang berpendapat bahwa lebih memilih menelepon radio, daripada Senkom untuk menginformasikan kejadian atau keadaan lalu lintas di sepanjang Tol ABC (6,99\%). Adapun beberapa pelanggan ternyata masih belum mengetahui adanya layanan Senkom $(28,88 \%)$, mereka berpendapat bahwa selama di Tol kurang memperhatikan adanya informasi nomor telepon Senkom $(21,88 \%)$.

Layanan transaksi adalah layanan yang diberikan oleh PT XYZ dalam pembayaran tarif tol, dengan menempatkan petugas di gerbang-gerbang Tol di sepanjang Tol ABC. Berdasarkan hasil survey dalam Gambar 6, dapat diketahui bahwa sebagian besar pelanggan tidak memiliki saran utuk layanan transaksi $(58,36 \%)$, di mana mereka berpendapat bahwa layanan transaksi yang diberikan sudah cukup cepat $(29,79 \%)$, sesuai harapan $(11,85 \%)$ dan sudah baik $(16,72 \%)$. Di samping itu, sebanyak $41,64 \%$ pelanggan perlu memberikan saran untuk meningkatkan layanan transaksi. Mereka berpendapat bahwa beberapa petugas kurang sigap $(2,74 \%)$ dan kurang ramah $(38,91 \%)$.

Layanan lalu lintas adalah layanan yang diberikan pengelola Tol ABC terkait dengan Patroli Jalan Raya (PJR), marka jalan, rambu dan informasi lalu lintas. Berdasarkan hasil survey dapat diketahui bahwa sebagian besar pelanggan tidak memiliki saran untuk layanan lalu lintas $(66,57 \%)$, di mana mereka berpendapat bahwa layanan lalu lintas Tol ABC sudah baik (44,98\%) dan sudah bagus (21,58\%). Adapun sebanyak 33,43\% pelanggan perlu memberikan saran perbaikan untuk meningkatkan layanan lalu lintas Jalan Tol ABC, yaitu penambahan lampu penerangan (10,94\%), patroli harus sering dilakukan $(11,25 \%)$, petugas PJR harus tegas terhadap pengendara yang melanggar marka atau rambu-rambu lalu lintas $(5,47 \%)$, serta respon dari petugas diharapka lebih cepat dalam menangani suatu kejadian lalu lintas di sepanjang Tol ABC $(5,78 \%)$. 
Layanan konstruksi adalah layanan yang disediakan PT. XYZ terkait dengan infrastruktur jalan dan rest area yang disediakan di sepanjang Tol ABC. Hasil survey menyatakan bahwa sebanyak 50,91\% pelanggan Tol menyatakan tidak ada saran untuk layanan konstruksi Tol ABC, mereka berpendapat bahwa infrastruktur yang ada sudah bagus $(23,10 \%)$ dan mereka cukup puas dengan kinerja pengelola dalam menangani permasalahan infrastruktur Jalan Tol ABC (27,66\%). Namun di sisi lain, hampir separo pelanggan menyatakan bahwa infrastruktur Tol ABC masih perlu diperbaiki (49,09\%). Mereka berpendapat bahwa masih banyak jalan yang bergelombang $(23,10 \%)$, sehingga diperlukan perbaikan segera $(11,85 \%)$, serta pengecekan kondisi jalan secara berkala $(14,29 \%)$.

Jalan Tol merupakan jalan penghubung antar daerah untuk memperpendek jarak tempuh dari suatu daerah ke daerah lain. Jalan Tol biasanya tidak berdiri sendiri, namun juga berhubungan dengan jalan Tol lain yang menghubungkan ke wilayah lain. Dalam hal ini juga termasuk Ruas Tol ABC yang dikelola oleh PT XYZ, berhubungan dengan Ruas Tol DEF yang dikelola PT UVW.

Berdasarkan hasil survey dapat diketahui bahwa sebagian besar pelanggan Tol ABC pernah melewati Tol DEF dengan frekuensi jarang sekali $(39,82 \%)$, kadangkadang (32,52\%), pernah sekali $(11,55 \%)$, sering $(7,9 \%)$, dan sering sekali $(4,56 \%)$. Adapun sebesar 3,65\% belum pernah melewati Tol DEF. Dari 96,35\% pelanggan Jalan Tol ABC yang pernah melewati Jalan Tol DEF, memberikan penilaian tentang pengalaman atas layanan yang dirasakan selama berkendara di sepanjang Jalan Tol DEF menyatakan bahwa kategori layanan Tol DEF yang dinilai oleh Pelanggan Tol ABC, masing-masing memiliki nilai indeks kepuasan antara 3,61 sampai 3,95, di mana nilai tersebut masih termasuk dalam kategori tidak puas. Nilai indeks terendah terdapat pada layanan konstruksi, yaitu 3,61, sedangkan nilai indeks tertinggi terdapat pada layanan kecepatan tempuh. Meskipun nilai indeks dari 15 kategori layanan termasuk dalam kategori tidak puas, namun apabila kita cermati pada tabel 14, dari 15 kategori layanan Tol DEF, yang dinilai oleh pelanggan Tol ABC, lebih dari 50\% menjawab dengan kategori puas, sangat puas, dan sangat puas sekali. Hal ini tentunya bisa dijadikan acuan untuk PT. XYZ, selaku pengelola Tol ABC untuk terus berinovasi mengembangkan infrastruktur dan layanan di sepanjang Tol ABC, sehingga pengguna Tol ABC tetap dapat merasakan kenyamanan dan keamanan berkendara, dibandingkan saat berkendara di Ruas Tol lainnya. Dari penjelasan di atas dapat disimpulkan bahwa setiap perusahaan, terutama perusahaan jasa harus terus melakukan inovasi produk layanannya, karena perusahaan pesaing juga terus melakukan inovasi, sehingga dengan tetap menjaga keunggulan dalam persaingan, maka akan menjadikan perusahaan menjadi perusahaan yang berdaya saing, terutama di mata para pelanggannya, serta mendorong pelanggannya untuk tetap loyal. 
Gambar 1: Indeks Kepuasan terhadap Layanan Tol Pembanding (Tol DEF)
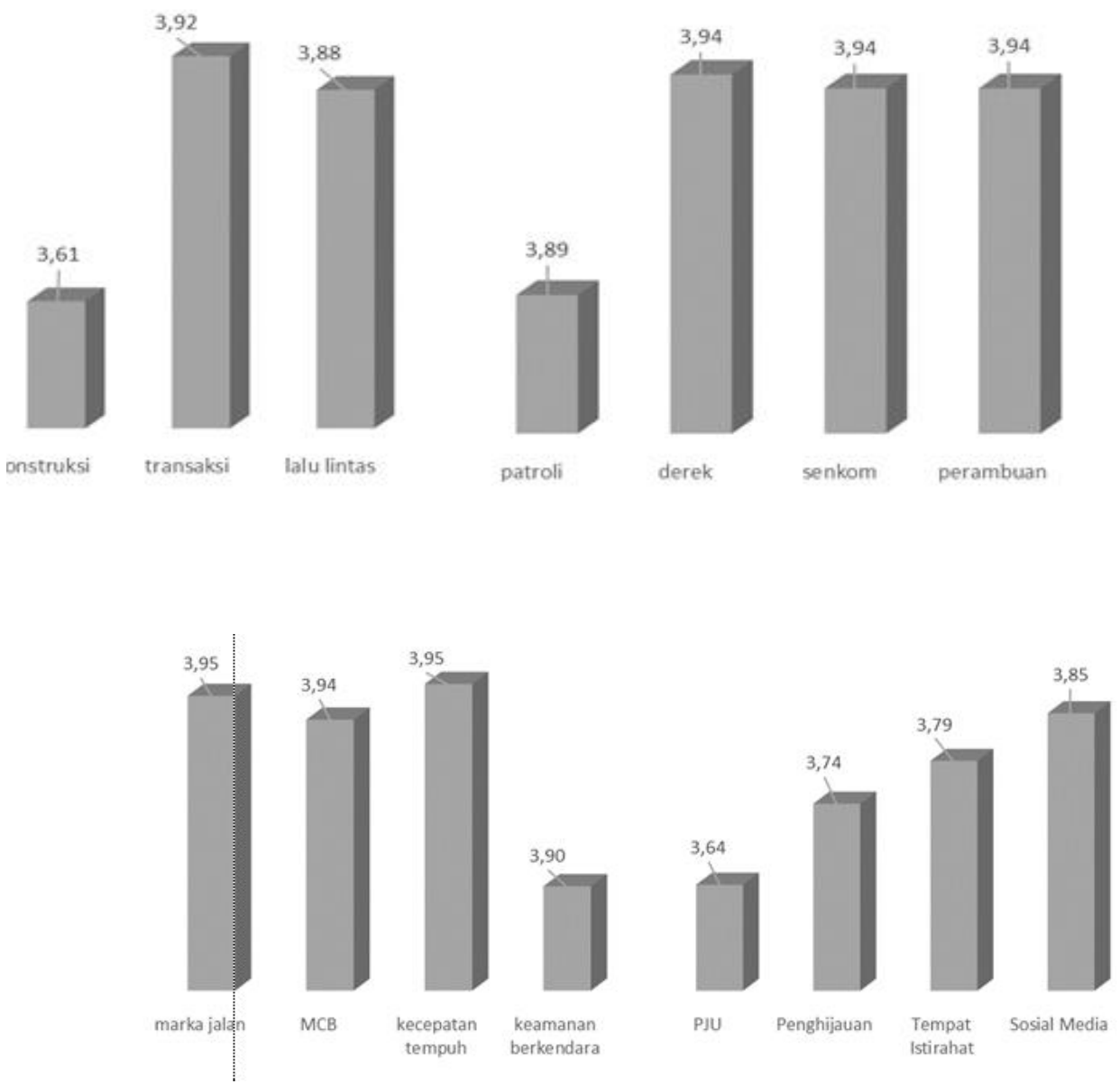

Gambar 2: Saran untuk layanan konsumen
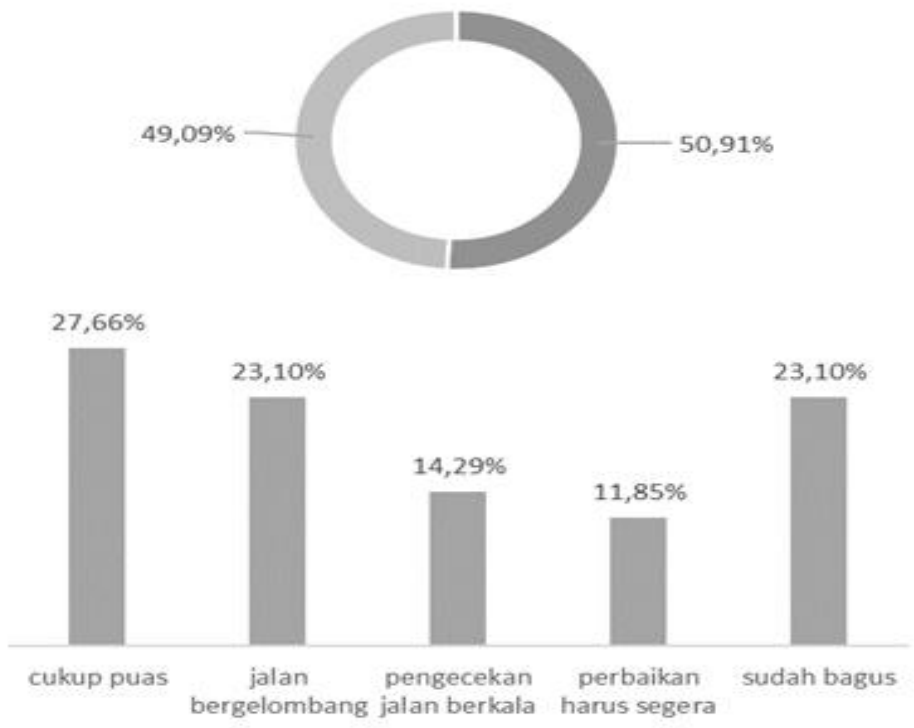

COMVICE, Vol 2 No 1, April 2018

http://ejournal.stiedewantara.ac.id/index.php/COMVICE/article/view/123 


\section{PENUTUP}

Berdasarkan hasil survey yang dilakukan, maka perlu dilakukan peningkatan sosialisasi penggunaan E-Payment, isi ulang E-Toll Card dan pemanfaatan GTO untuk meningkatkan transaksi pembayaran tarif tol secara non tunai, untuk mempercepat transaksi, dengan harapan dapat mengurangi antrian di gerbang tol. Selain itu, perlu dilakukan peningkatan sosialisasi tentang layanan dan teknis jasa derek gratis dan layanan senkom, sehingga dapat membantu pelanggan yang mengalami kerusakan mesin kendaraan di sepanjang Tol $\mathrm{ABC}$, ataupun partisipasi aktif pelanggan dalam menginformasikan kondisi lalu lintas di sepanjang Tol ABC. Kemudian juga Perlunya pelatihan petugas gardu tol untuk meningkatkan keramahannya saat melayani pembayaran tarif tol, penambahan PJU, penambahan frekuensi patroli petugas PJR, peningkatan respon petugas terhadap kejadian di sepanjang Tol ABC, perbaikan jalan yang bergelombang agar tidak membahayakan pengendara, serta pengecekan infrastruktur secara berkala. Inovasi produk layanan juga hendaknya terus dilakukan, mengingat penilaian pelanggan Tol ABC terhadap layanan Jalan Tol Pembanding semakin baik, meskipun masih tergolong dalam kategori tidak puas. Dengan terus melakukan inovasi secara berkelanjutan, maka PT. XYZ dapat terus memberikan kenyamanan berkendara yang lebih baik kepada pelanggan saat berkendara di sepanjang Tol ABC.

\section{DAFTAR PUSTAKA}

Hansen dan Mowen. (2001). Akuntansi Manajemen. Erlangga. Jakarta

Maholtra, N. (2005). Riset Pemasaran: Pendekatan Terapan. Indeks. Jakarta

Lupiyoadi, R. (2013). Manajemen Pemasan Jasa. Penerbit Salemba Empat. Jakarta

Tjiptono, F. (2015). Pemasaran Jasa: Prinsip, Penerapan, Penelitian. Penerbit Andi. Yogyakarta

Rofiah, C., \& Wahyuni, D. (2017). Kualitas Pelayanan Dan Pengaruhnya Terhadap Loyalitas Pelanggan Yang Di Mediasi Oleh Kepuasan Di Bank Muamalat Jombang. Eksis: Jurnal Riset Ekonomi dan Bisnis, 12(1 Apr).

Rohim, A., \& Arvianto, S. (2017). Pengaruh Customer Perceived Value Terhadap Word Of Mouth Dengan Customer Loyalty Sebagai Variabel Mediasi (Study Kasus Di CV Putra Putri). Eksis: Jurnal Riset Ekonomi dan Bisnis, 12(1 Apr). 